\title{
Summertime winds and direct cyclonic circulation: observations from Lake Geneva
}

\author{
U. Lemmin, N. D'Adamo ${ }^{1}$ \\ Laboratoire de recherches hydrauliques, Ecole Polytechnique Fédérale de Lausanne, CH-1015 Lausanne, Switzerland
}

Received: 11 March 1996/Revised 7 June 1996/Accepted: 14 June 1996

\begin{abstract}
Records of wind, air temperature and air pressure from nine stations, situated along the shoreline of Lake Geneva, Switzerland, were analyzed for the summer period May to September. At all stations the consistent appearance of significant spectral peaks and changes in wind direction at the diurnal frequency indicates the importance of lake-land breezes. It is shown that the surrounding topography has a strong modifying effect (temporal and spatial) on the lake-land breeze. Superimposed on this cyclic wind pattern, short episodes of strong winds with long fetch over parts of Lake Geneva are regularly observed. Both of these winds exert a spatially variable wind stress over the lake surface on the same time scale. Typical examples of the expected lake's response are presented, among them the seasonally persistent gyre in the central part of the lake. Evidence is provided that this dominant circulation is part of a direct cyclonic circulation, generated by the curl of the diurnal wind field. It is concluded that the mean circulation is caused by these winds and affected by the topography of the surrounding land.
\end{abstract}

\section{Introduction}

In this study we analyze and interpret wind data recorded around Lake Geneva and baroclinic motion in the lake obtained from moored current meter records. In order to determine the type of circulation that will be established in the lake in response to a particular wind forcing a knowledge of the characteristics of the wind field is important. This was already obvious to Forel (1895), who coined the term 'limnology', in his fundamental investigations of the movement of water and its relationship to water quality in stratified lakes using Lake Geneva as 'field laboratory'. The influence of winds on the hydrodynamics of lakes has

\footnotetext{
${ }^{1}$ Present address: Environmental Protection Agency, Perth 6009, Australia

Correspondence to: U. Lemmin
}

been the subject of many limnological studies since, both in the field (Mortimer, 1974; Fischer et al., 1979; Imberger and Hamblin, 1982) and in the laboratory (Monismith, 1983). Accurate knowledge of the strength and the spatial and temporal distribution of winds is needed as input into numerical lake models. The assumption of a constant wind stress is only rarely justified (Simons, 1980). As Mortimer (1979, p. 214) pointed out, "Wind stress and its horizontal distribution over the whole water surface is the critical variable and is usually the least well defined."

It is recognized that the kinetic energy introduced at the water surface by way of wind shear stress is of prime importance in mixing the water vertically, accelerating the water horizontally in the form of barotropic flows and in setting up a spatially variable horizontal density field, hence inducing baroclinic adjustments of the density structure as the stratification relaxes after a forcing event. The particular response of the lake depends on the characteristics of the forcing event.

This work presents the results of an analysis of a series of summer time winds from several stations situated around the shorelines of the Lake Geneva basin. Lake current data are scrutinized for evidence of the expected circulation patterns. We shall show that it is essential to represent the wind field on the scale of the major surrounding topography if the observed mean lake circulation is to be explained.

\section{Background}

\section{Wind field}

The summer wind field over a lake is, in general, dominated by event-structured contributions on two rather different scales. The first type of wind is related to the passage of synoptic scale pressure cells. The time and length scales of these wind events are typically much larger than the lake basin and in a first order approximation it can be assumed that these winds are homogeneous over the lake. Topographic constraints may have some effects. 
The second type of wind, the land-lake breeze, is a thermally induced wind. It is generated on scales which are comparable to the lake basin itself. Since these winds act simultaneously around the whole perimeter of the basin and perpendicular to the shoreline, the wind field will not be homogeneous over the lake. Due to the way it is generated locally this wind field is also more sensitive to local topographic effects which may cause a curl.

The first type of wind field often produces much higher wind velocities than those typical for the second type of wind field. As a consequence it can be expected that the lake will respond differently to the two types of forcing. In order to characterize a particular wind field the typical spatial and temporal scales and strengths have to be established in the data analysis. This will be done here by statistical analysis, particularly spectral analysis.

\section{Lake circulation}

The dynamic response of a stratified lake depends upon the intensity and the fetch length of the wind, the ambient stratification and the geometry of the lake. Here we will limit ourselves to lakes with length scales between 10 and $100 \mathrm{~km}$ where the internal Rossby radius of deformation is less than the width of the basin (a typical value for Lake Geneva is $\mathrm{O}(5) \mathrm{km})$. Consequently the Coriolis force will affect the lake's response pattern to the wind forcing.

For homogeneous, high wind speeds related to the passage of large-scale synoptic pressure cells upwelling, downwelling and rapid vertical entrainment are predicted. The baroclinic motion which results from the pressure force caused by the internal surface slanting due to upwelling and downwelling, affected by the Coriolis force, will create cyclonic circulation. Interface tilting leads to internal Kelvin waves (Mortimer, 1953), traveling cyclonically around the basin. The instantaneous currents associated with the passage of these waves are at times much larger than the long term mean values averaged over several wave periods. As a result Kelvin waves induce only a weak mean circulation. This type of lake response has been termed "residual" circulation (Cheng and Casulli, 1982). Numerical simulations (Simons, 1975; Huang and Sloss, 1981) as well as observations (Pickett and Richards, 1975) from the Great Lakes, North America, show that a constant wind stress causes a long-lasting gyral circulation. If the wind is strong a two-gyre pattern is initially forced which relaxes to a one-gyre pattern over most of the lake when the wind decreases.

For the case of a wind field with a curl over a stratified lake, most likely to occur with the lake-land breeze wind regime, Strub and Powell (1986) have shown through numerical simulation for Lake Tahoe, USA, that the current structure generated in a stratified lake differs greatly from that generated by a constant wind stress. Even though once again a basin-wide circulation in a gyral pattern is found for a wind stress distribution with a curl, this circulation pattern differs from the residual circulation in several important aspects: it is characterized by steady currents similar in magnitude and direction to the instantaneous velocities. The circulation extends well into the metalimnion. Amplitudes of the vertical displacements of internal density surfaces are small. This type of water movement was termed "direct" circulation by Strub and Powell (1986).

The important difference between residual and direct circulation resides in the transfer of energy from the wind into the circulation: in residual circulation the wind energy is first transformed into available potential energy in the slanted internal density surfaces and then transformed further into the kinetic energy associated with the gyres. In direct circulation it is more efficiently transferred directly to the rotational currents (Strub and Powell, 1986). Verification of the Lake Tahoe simulation result by field observations is not presently available. Here we conclude that the lake response to inhomogeneous and variable winds often observed over lakes requires further study. We will therefore first analyze the wind field for the presence of a curl. The current data will then be tested for aspects of the direct circulation.

\section{Lake Geneva}

\section{The site}

Lake Geneva is situated in the southwest of Switzerland (Fig. 1). It is curved in shape, and it is composed of two main basins: a relatively small section in the west called the Petit Lac ('small lake'; maximum depth $70 \mathrm{~m}$ ) and a larger section in the east called the Grand Lac ('big lake'; maximum depth $300 \mathrm{~m}$ ). The lake has a maximum length and width of 72.3 and $13.8 \mathrm{~km}$, respectively. Important to the wind-related hydrodynamics of the lake are the topographical features which surround the shores. Around the eastern and southern parts of the lake are the Alps, with elevations of more than $1000 \mathrm{~m}$ above the lake level and with individual peaks of that height within $2 \mathrm{~km}$ from shore. The eastern half of the lake is sheltered by these high mountains from most of the winds that originate outside of the lake confines. To the northwest are the Jura mountains. The central and western part of the lake make part of a valley some $50 \mathrm{~km}$ wide which separates these mountain formations to the north and east of the lake. The curved shape of the lake and the surrounding topography causes winds over the lake to exert a spatially variable stress. Local fishermen characterize a total of 22 different winds by specific names (LeFranc, 1923).

\section{Past studies}

Past studies of the wind field at Cointrin (hereinafter CO; Graf and Prost, 1979) have shown that there exists at least two separate identifiable directions (indicated in Fig. 1) of regularly occurring strong winds $\left(\mathrm{O}>\left(5 \mathrm{~m} \mathrm{~s}^{-1}\right)\right)$. These are locally known as the 'vent' (hereinafter SW), a wind which comes from the southwest and enters the lake basin at the $\mathrm{CO}$ end, and the 'bise' (hereinafter NE) which blows in the opposite direction (Wanner and Furger, 1990). The $\mathrm{NE}$ and $\mathrm{SW}$ are winds with long fetch often observed in time series at $\mathrm{CO}$, Changin $(\mathrm{CH})$ and Pully (PU), but 


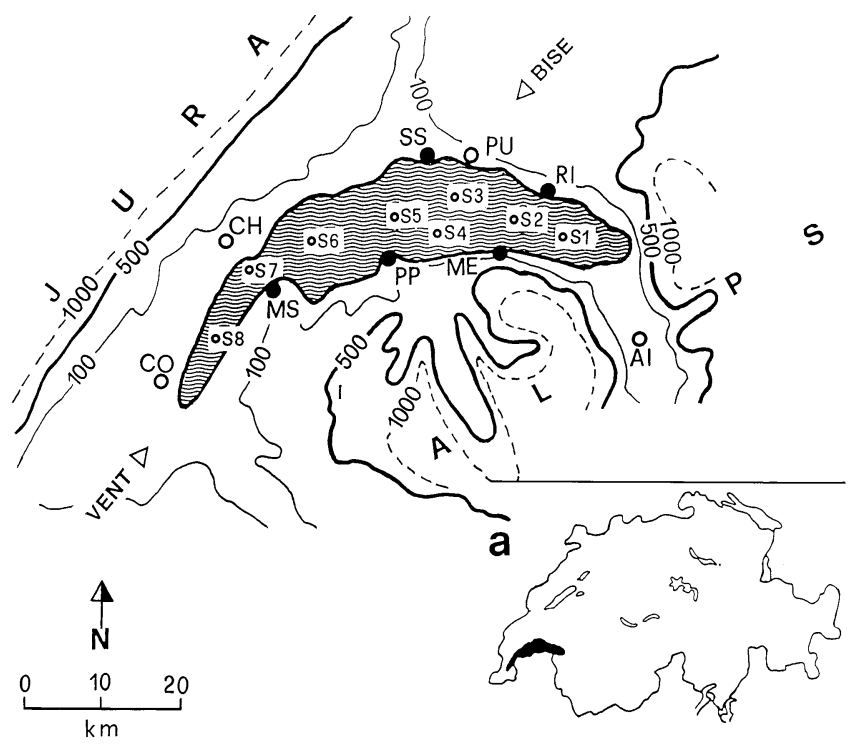

Fig. 1. Lake Geneva and its surroundings. The lake level $(348 \mathrm{~m}$ above sea level) is taken as reference for all heights or depths indicated. Locations of temperature profiling stations ( $S 1$ to $S 8)$ and of wind measuring stations are indicated. Letters represent: $A I$, Aigle; $\mathrm{CH}$, Changins; $\mathrm{CO}$, Cointrin and $\mathrm{PU}$, Pully. a Location of Lake Geneva in Switzerland

hardly so at Aigle (AI). Both of these winds are associated with large-scale atmospheric pressure systems typically passing at intervals of several days. While they are strongest during the winter months, they also occur during summer with less pronounced frequency and strength. Bohle-Carbonell (1991) has analyzed fall and winter wind and (barotropic) current data. He found that during the cold seasons of the year the wind field is organized on mesoscales and that the current field is noisy, patchy and not organized on basin-wide scales. Some fundamental aspects of land-lake breezes over Lake Geneva have been discussed by Ganter (1978).

Tracer observations in Lake Geneva (Rapin et al., 1978) have indicated a westward water transport along the northern shore of the lake and it has been argued that this is due to the passage of the Rhone river through the lake being deflected by the Coriolis force. However, considering the 12 year water-residence time of the lake, a stronger steady current is needed to explain this sediment pattern. We will address this point in our analysis.

\section{Data base}

\section{Meteorological data}

Wind data were obtained from the 9 wind stations indicated in Fig. 1 by letters.

The AI, PU, $\mathrm{CH}$ and $\mathrm{CO}$ wind data, along with accompanying meteorological data, were provided by the Swiss Meteorological Institute (ISM). The remaining stations were installed for this study on steam boat landings extending 20 to $40 \mathrm{~m}$ into the lake to about $4 \mathrm{~m}$ water depth.
They recorded the wind vector and the air temperature at about $10 \mathrm{~m}$ above the water surface.

The data were recorded as either 10 or $30 \mathrm{~min}$ averages. Half-hourly or hourly averages derived from them have been used for the present analysis. The wind data set used in this study encompasses the period from 1981 to 1987. None of stations provide year-long gap-free records and data gaps are larger in the records from the boat landing stations. However, there is a sufficient number of relatively long and uninterrupted data periods so that comparisons can be made between stations, for proper spectral analyses and for investigations of the spatial distribution of winds during events.

\section{Current data}

Current measurements have been carried out in Lake Geneva over the past 15 years, most of them on the Swiss, northern shore of the lake. During the period of strong stratification most recordings were made with only one mooring at a time holding several instruments at different depths. Station locations and observation times are indicated on Fig. 10. In October 1986 simultaneous recordings at 8 stations in a cross section of the lake were carried out between SS and PP (Fig. 1). Stratification at this time of the year is still sufficiently close to the summer situation with a strong thermocline above $30 \mathrm{~m}$ depth.

\section{Analysis of meteorological data}

The present study provides an analysis of the summer wind fields around Lake Geneva in terms of their spatially and temporally variable characteristics in particular of lake-land breezes. Summer will be defined as the period during which lake stratification is well developed, i.e., from May to October (Lemmin et al. 1988).

In order to determine whether data from a single summer season are representative for the dynamics of the wind field over Lake Geneva we first analyzed the longer (and more complete) time series from the stations AI, PU, CH and $\mathrm{CO}$. The four stations are well positioned to capture wind information relevant to the NE, SW and local on and off-shore breezes. Rose diagrams and speed class histograms for all years are presented in Figs. 2 and 3 and were found to be typical for any single year. Generally, the four stations show strong directional preference for winds. At AI and CO (Fig. 2) winds occur predominantly along a line parallel to their respective elongated valleys suggesting that funneling of the winds is an important factor at these stations. At PU and $\mathrm{CH}$ winds occur predominantly along the two respective along-shore and across-shore axis. At PU the across-shore winds are dominant, their alignment being to or from 30 degrees. At $\mathrm{CH}$ the acrossshore and along-shore winds are roughly equally important. In the along-shore direction at $\mathrm{CH}, \mathrm{SW}$-winds dominate the signal in comparison to NE winds. In the across-shore direction, winds from either the land or the lake appear equally important. 


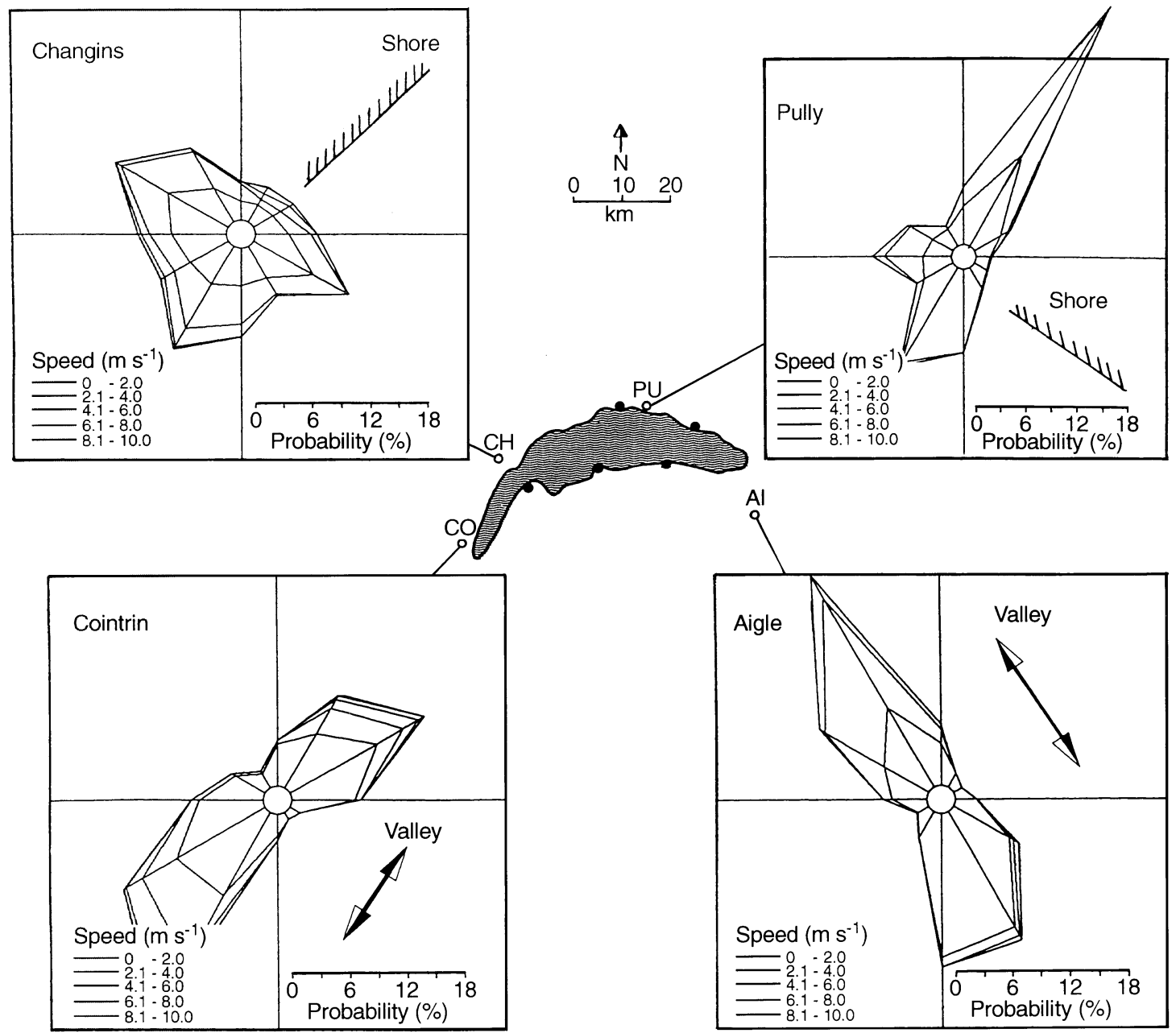

Fig. 2. Rose diagrams of the winds at the four Swiss Meteorological stations $C O, C H, P U$ and $A I$. Winds are shown as "coming from"

The histograms in Fig. 3 show that during summer the wind speeds were predominantly $<4 \mathrm{~m} \mathrm{~s}^{-1}$ (about 80 $90 \%$ of the time). In the eastern half and the central part of the lake basin, maximum winds are about $4-6 \mathrm{~m} \mathrm{~s}^{-1}$ and occurred for $5-10 \%$ of the time. In the western half of the lake maximum winds of about $4-8 \mathrm{~m} \mathrm{~s}^{-1}$ occurred about $10-15 \%$ of the time. Thus, along the northern boundary of the lake, winds appear generally stronger in the western half.

\section{Periodicity analyses}

Since dominant directions in the wind roses at all stations were identified, a spectral analysis was performed on the vector components of the wind velocity aligned parallel to their dominant directions. Figure 4 presents the alongshore and across-shore wind spectra for all the summer months for all four stations. They were found to be representative for any one month period, or any single year.

In general, the spectral analysis reveals that periodic winds occur along the northern shore of the lake from $\mathrm{CO}$ to AI and are predominantly across-shore. The dominant period for the four stations is 1 day (the diurnal fre- quency). The along-valley direction at $\mathrm{CO}$ and $\mathrm{AI}$ is taken as an across-shore direction, with winds at these stations crossing the shores at the lake ends of the respective valleys. At $\mathrm{AI}$ and $\mathrm{CO}$ most of the spectral energy is concentrated in the along-valley directions, as suggested in the wind roses for these stations (Fig. 2). The diurnal peak is least pronounced at $\mathrm{CO}$. At $\mathrm{CH}$ a significant spectral peak at the diurnal frequency is found for the along-shore as well as the across-shore direction (direction of positive wind vectors is towards the shore at $\mathrm{CO}$, $\mathrm{CH}, \mathrm{PU})$.

At the diurnal period, wind speeds of approximately $3 \mathrm{~m} \mathrm{~s}^{-1}$ are associated with all spectra except for the one at $\mathrm{CO}$, which has a speed of $1.5 \mathrm{~m} \mathrm{~s}^{-1}$. Coherent with the diurnal along-valley winds at $\mathrm{CO}$ the along-shore diurnal winds at $\mathrm{CH}$ again have an intensity of $1.5 \mathrm{~m} \mathrm{~s}^{-1}$. In addition, a $0.5 \mathrm{~d}$ period figures in the across-shore spectra of $\mathrm{AI}$ and $\mathrm{CH}$.

The wind speeds associated with spectral peaks in the low frequency end of the spectra $(T>1 \mathrm{~d})$ are smaller. The CO spectrum has the broadest spread of energy of the four stations. This reflects the elevated occurrence of winds forced by meso- and large-scale weather cells over the western half of the lake. Over the eastern part of the lake (PU and AI) low frequency winds are less developed indicating a topographical sheltering of that region. We will discuss this point in more detail. 

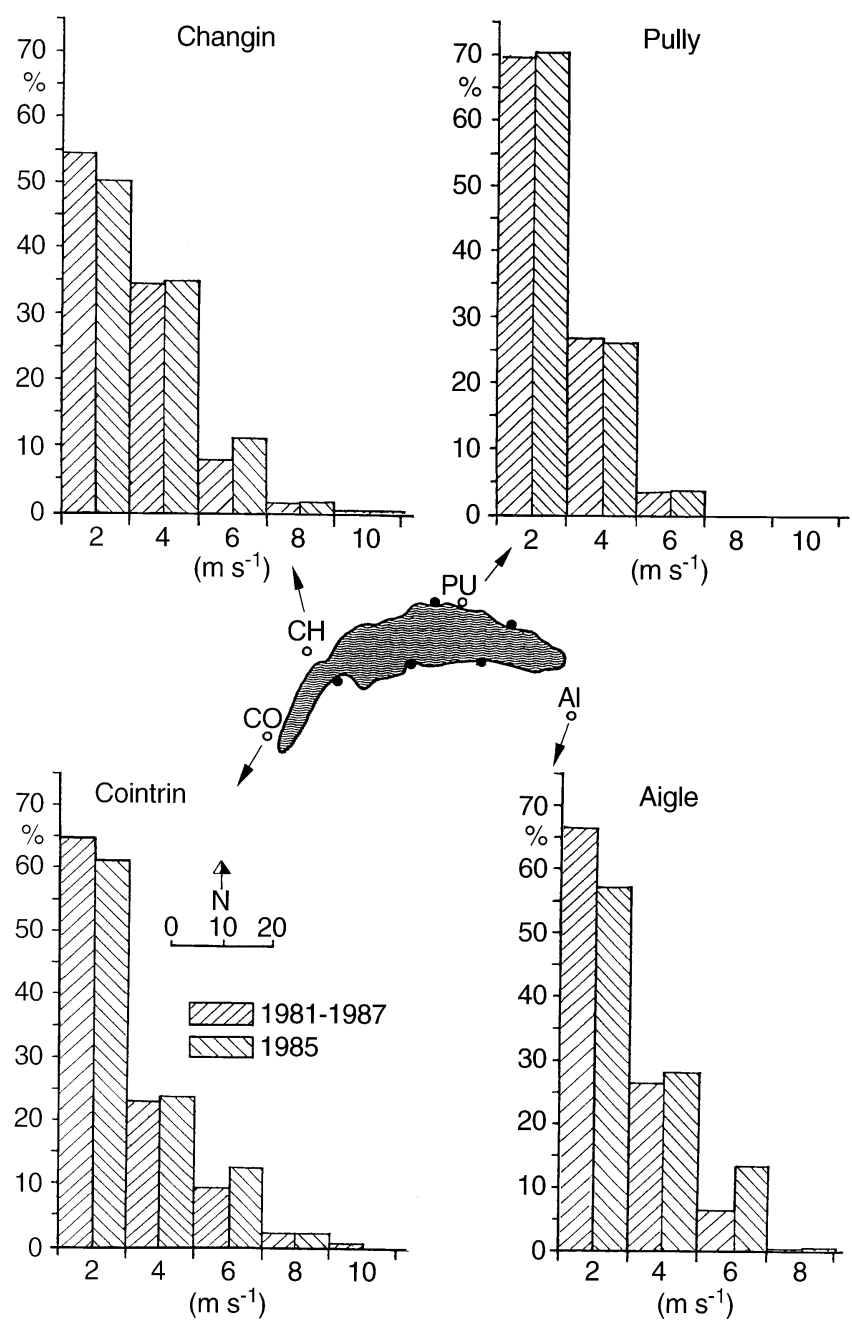

Fig. 3. Histograms of wind speeds at the four stations $\mathrm{CO}, \mathrm{CH}, \mathrm{PU}$ and AI for the summer period from May to September. The information extracted from the full record 1981 to 1987 as well as from the summer of 1985 only are shown

\section{Coherence of winds between stations}

Cross spectra between various along-shore and acrossshore components of the wind field at different stations were calculated to investigate spatial coherence. By far the greatest overall coherence was found for the $\mathrm{CO}$ alongvalley/ $\mathrm{CH}$ along-shore pair and the $\mathrm{CH}$ along-shore/PU along-shore components. In contrast, the across-shore components of $\mathrm{AI}, \mathrm{PU}$ and $\mathrm{CH}$ exhibit a very high coherence at the diurnal frequency but relatively low coherence otherwise. This suggests that there is coherence between summer time across-shore breezes around the northern periphery of the Grand Lac. While $\mathrm{CH}$ and PU are in phase at the diurnal frequency, a $180^{\circ}$ out-of-phase relation is found between PU and AI at that frequency. The diurnal forcing at AI is probably due to cold mountain air gravitating down towards the lake. Hence the time between generation and arrival of this wind at AI is likely to be different from the time for the generation and on-shore presence of the local land-lake breezes along the northern lake periphery.

The $\mathrm{CH}$ across shore/CO along valley pair, which would represent the land breeze-lake breeze pair over the Petit Lac, does not exhibit any correlation at the diurnal frequency. The topography around $\mathrm{CO}$ is much flatter than that at AI and the adjacent water area is smaller near $\mathrm{CO}$ than at the other stations; these factors may be responsible for the low correlation.

\section{Coherence of winds with temperature}

From this investigation it is evident that the summer wind field along the northern shoreline of Lake Geneva is strongly characterized by across-shore diurnal winds. Correlations between the air temperature and the wind components are calculated to determine in which way these winds are thermally forced by differential heating between the air over the lake surface and that over the surrounding peripheral land.

The temperature spectra for all stations are similar (Fig. 5) and exhibit two peaks of significance; one at a period of 1 day and one that is less pronounced at approximately 10 days. The diurnal signal reflects daily solar heating and the 10 day temperature periodicity is probably associated with the large-scale weather systems that regularly pass over the European continent.

The across-shore wind spectra, with the exception of $\mathrm{CO}$, show high coherence with temperature at periods of 1 and 0.5 days (Fig. 5). Comparing the results of crossspectral analysis on the respective $\mathrm{CH}$ across-shore/temperature and $\mathrm{CH}$ along-shore/temperature pairs at the diurnal period shows that temperature is coherent to almost unity for $\mathrm{CH}$ across-shore compared to a coherence of 0.70 for $\mathrm{CH}$ along-shore. This suggests that the temperature signal is more strongly related to the acrossshore breezes. This effect is even more pronounced at PU and AI. At PU the phase angle between the temperature and the across-shore wind component is about $90^{\circ}$ with the temperature leading. At $\mathrm{CH}$ this angle is about $60^{\circ}$. At AI, located in the Rhone valley, the time lag is zero. Therefore winds at AI are not forced by the lake-land breeze effect. This point will be further addressed in the following section. The absence of strong coherence between the $\mathrm{CO}$ along-valley and temperature spectra at the diurnal frequency (Fig. 5) implies that the lake-land breeze effect is less effective on the Petit Lac and local surroundings. The reduced water surface area relative to that in the Grand Lac may be one reason for this.

\section{The diurnal wind field around the lake}

From the analyses it became obvious that the diurnal winds generated by differential heating are the most important components of the summer wind field. Generally it is assumed that these winds are forced to propagate perpendicular to the shore, as was the indication from the rose diagram at $\mathrm{CH}$ (Fig. 2). However, as was already indicated by the rose diagram at PU (Fig. 2), topographic 

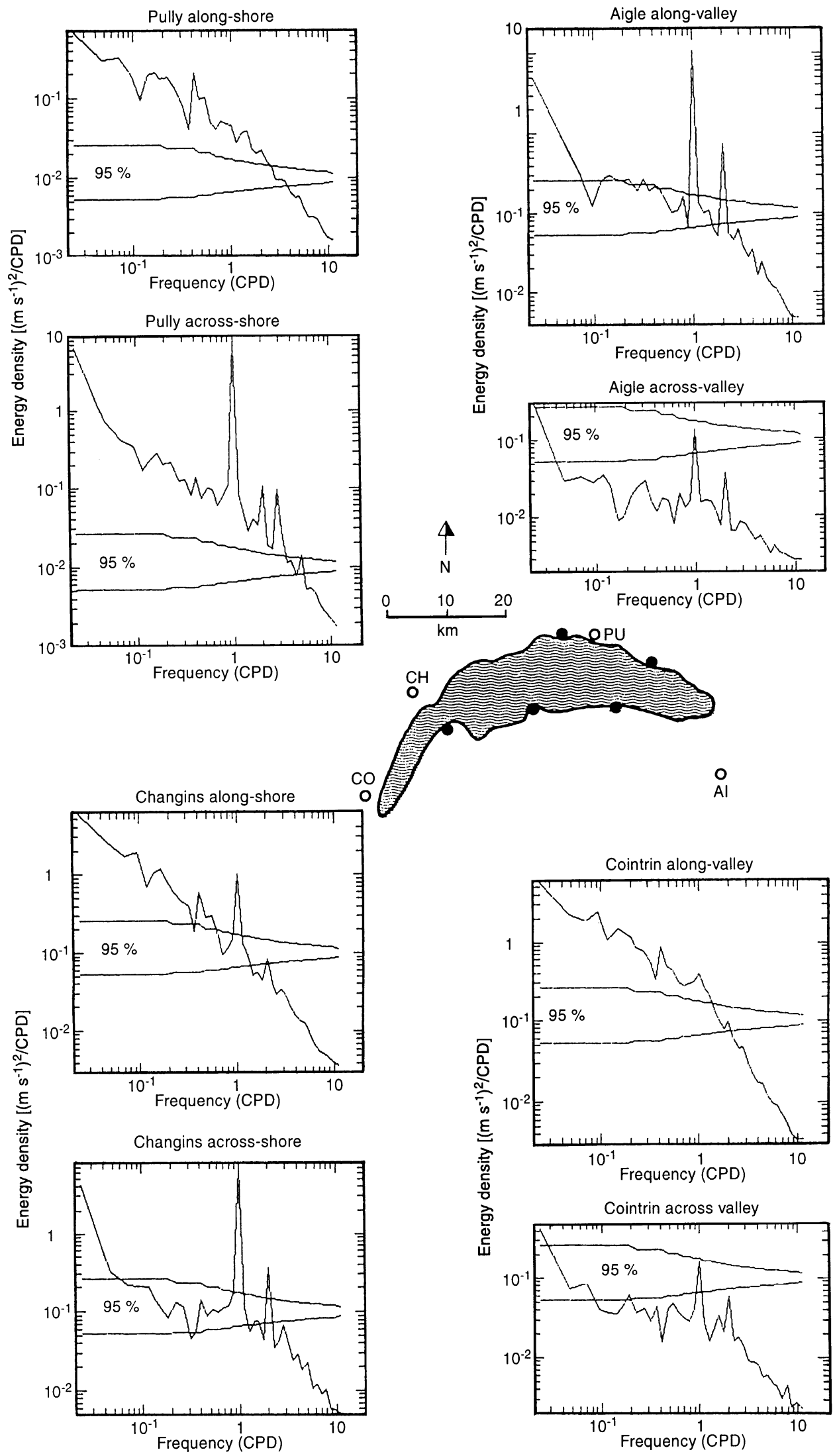

Fig. 4. For the summer of 1985 : spectra of the two components of the wind vector at the four Swiss Meteorological stations $\mathrm{CO}, \mathrm{CH}$, $P U$ and $A I$ 

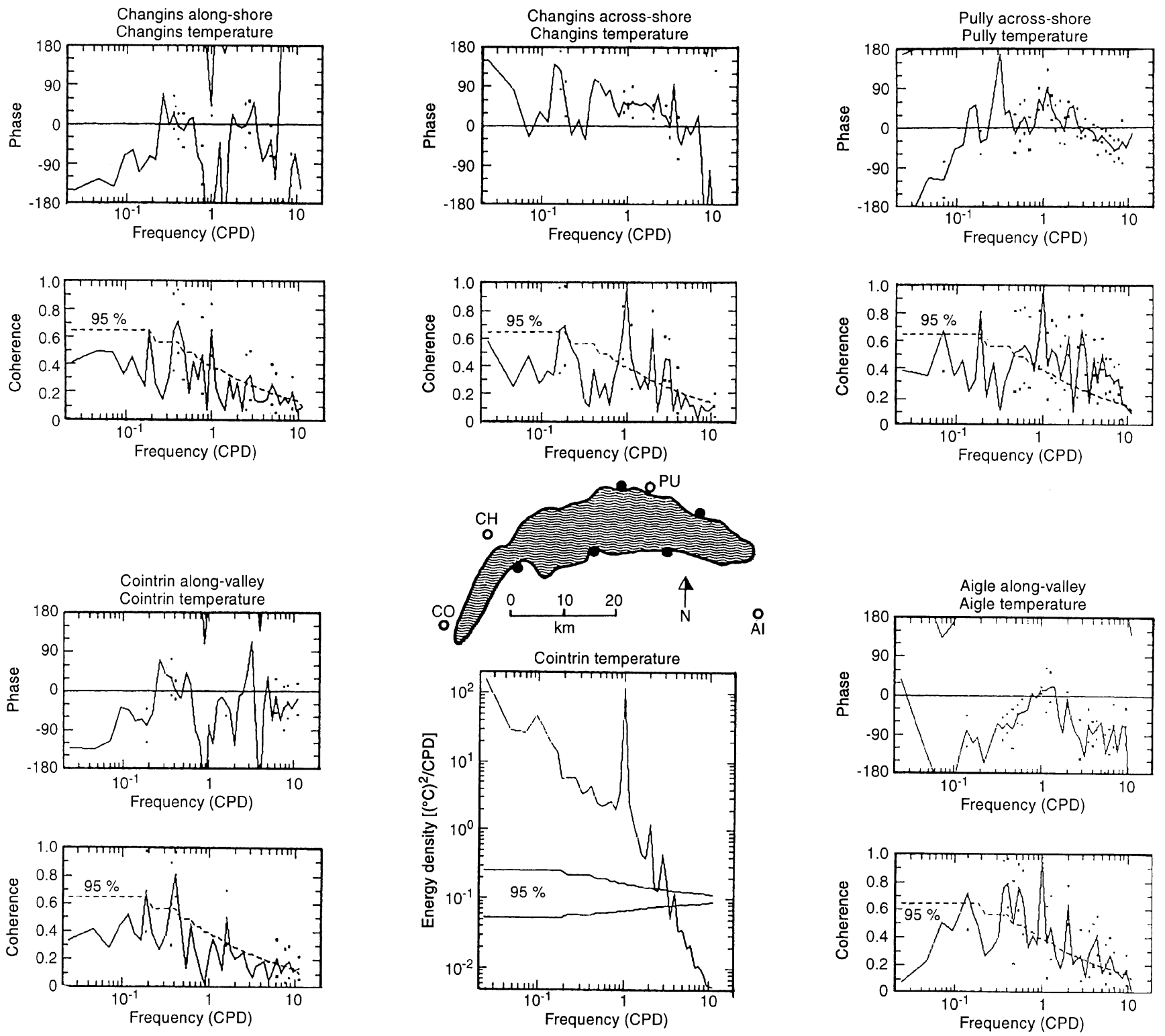

Fig. 5. For the summer of 1985: coherence and phase between wind vector components and air temperature at the four stations $\mathrm{CO}, \mathrm{CH}$, $P U$ and $A I$

effects may locally change this orientation. In order to learn more about the topographic effects around the lake, the wind records from the 5 steamer landing stations (RI, ME, SS, PP and MS, Fig. 1) were analyzed. As was mentioned, gaps occurred in these data records and these were due to vandalism and malfunction of the instruments. However, in the summer of 1986 all instruments worked for 7 weeks between 10 July and 31 August. From the earlier discussion this record can be considered representative of the typical summer conditions.

In order to provide more detail on the dynamics of the diurnal wind field, mean vectors for each hour of a $24 \mathrm{~h}$ day were calculated over the total observation length of 49 days. This procedure effectively filters out the effect of any long-term wind field and reveals the diurnal structure which we are interested in at present. The resultant wind vector distribution is shown in Fig. 6. Along the north shore the diurnal wind pattern is well established. At $\mathrm{CH}$ maximum wind speeds during the day and the night are about equal. At SS and PU nocturnal maxima are much higher than daytime winds.

Moving eastward the funneling effect of the Rhone valley becomes obvious. The theory of valley winds (Defant, 1951) predicts that compared to the lake-land breeze the valley winds start earlier in the morning and continue later into the evening. For the same radiation input they produce stronger wind velocities than the lake-land breeze. These features are well documented when comparing the valley wind at $\mathrm{AI}$ with the lake-land breeze at $\mathrm{Pu}$. The out of phase relationship between diurnal winds at PU and at AI noted already is seen in this diagram. The valley winds have the highest mean speeds in the diurnal pattern recorded around the lake. The effect of this strong valley wind extends over the eastern part of the lake and forces also the daytime winds at RI to be oriented towards the Rhone valley. 


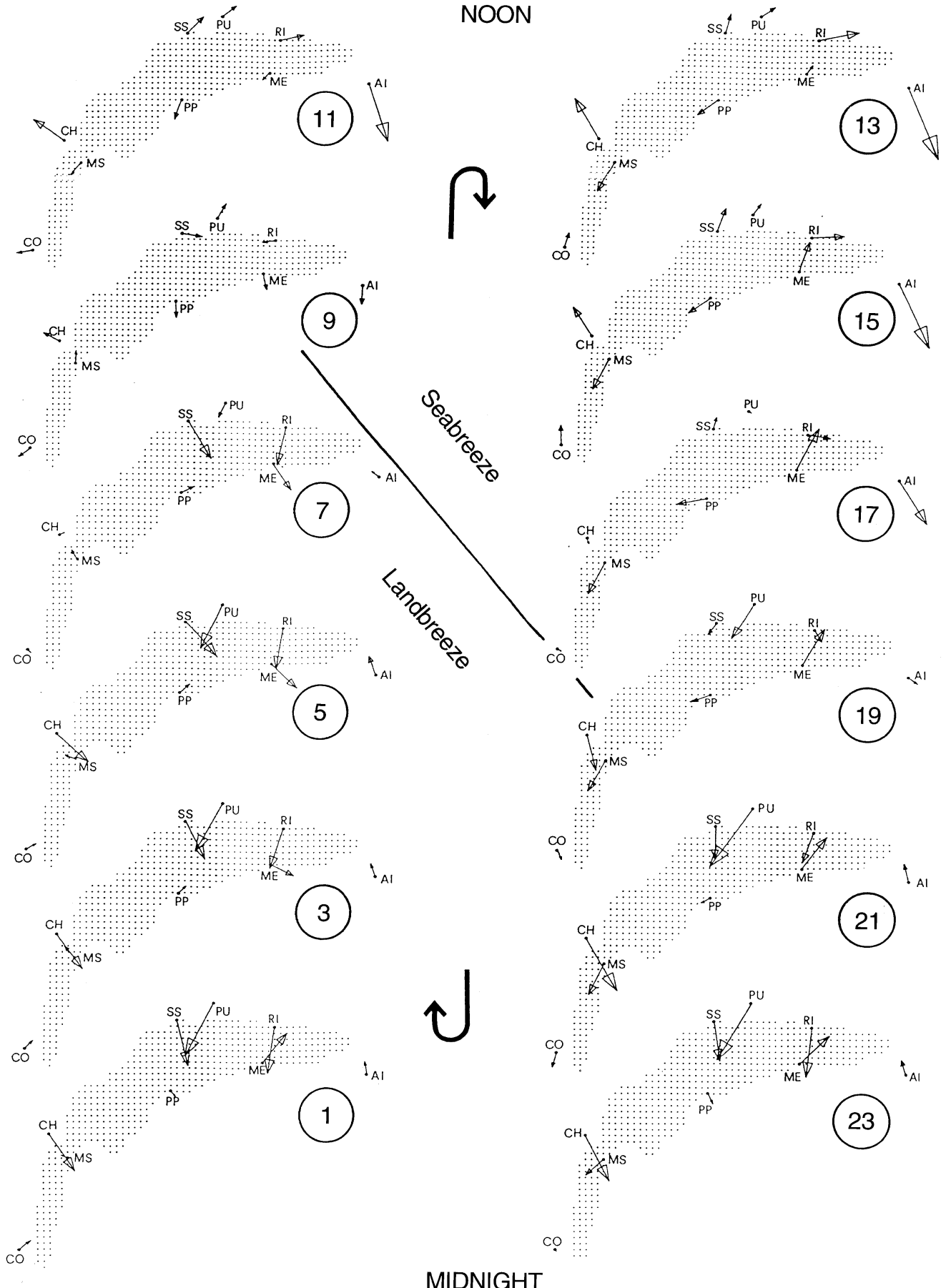

MIDNIGHT
Fig. 6. A typical wind field around Lake Geneva. By averaging for each hour of the day over 45 days (from July to August 1986) 24 hourly mean wind vectors at all stations were derived. The corresponding hour of each diagram is circled
At ME opposite RI on the south shore this effect of the Rhone valley is less evident. Here another local phenomenon comes into play. As can be seen from Fig. 1 the mountain slope behind $\mathrm{ME}$ is rather steep and thus $\mathrm{ME}$ becomes shaded in the early afternoon. This cooling leads to a local time shift in the diurnal pattern compared to the rest of the lake. At PP and MS wind vectors appear to be correlated during the time when velocities are high. In that case, which occurs during the afternoon and the early evening winds are oriented parallel to the local shoreline. No firm explanation for this vector orientation can be given. However, assuming that wind speed will increase with fetch over the lake (Richards et al., 1966; Schwab and Morton, 1984), it is possible that winds from the opposite northern shoreline dominate over the lake and reorient winds at PP and MS by blowing strongly towards this southern shoreline. At the end of the small lake basin (CO) wind speeds are low and the diurnal structure is not developed.

From this mean vector diagram (Fig. 6) spatial and temporal variability of the diurnal wind field over the lake is indicated. It is observed that during the second part of 


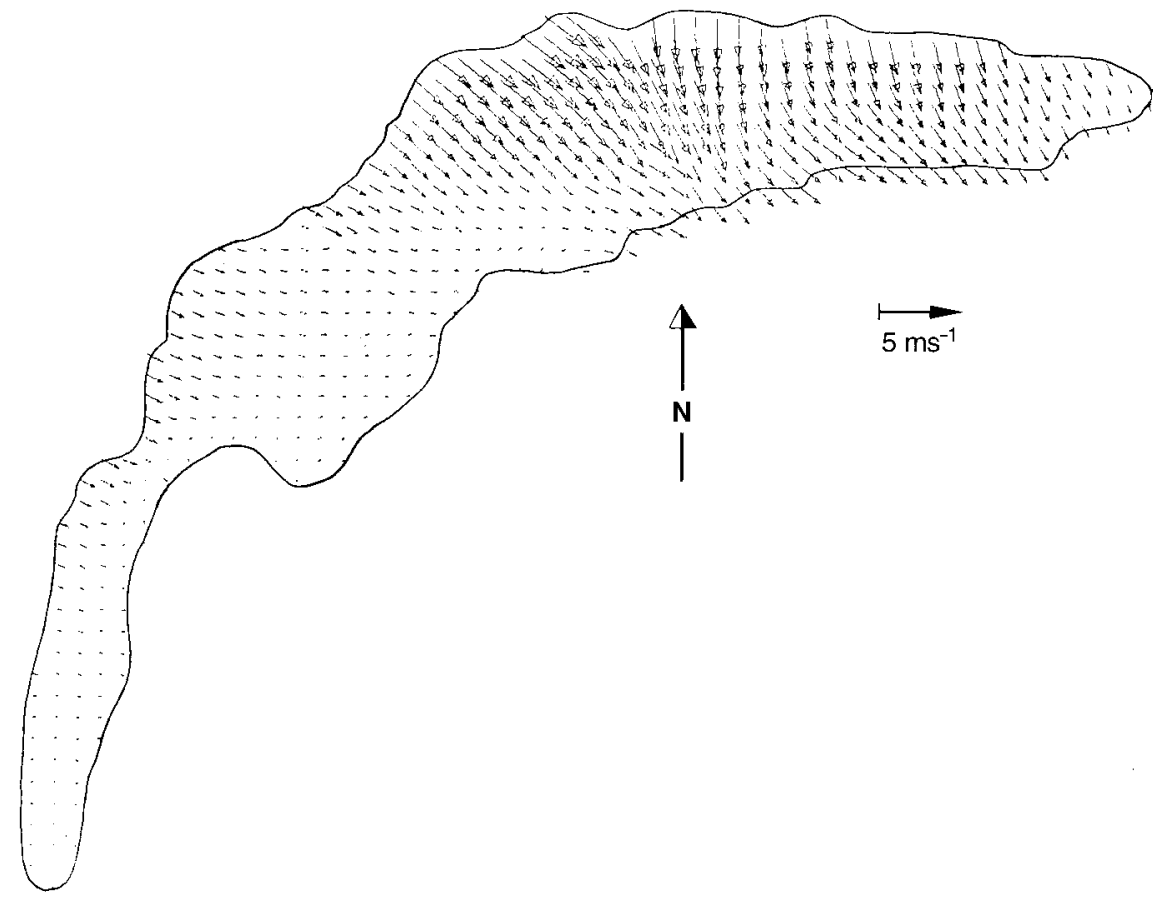

Fig. 7. A typical early morning (3:00) wind field over the lake constructed from wind data measured at the stations around the lake (see Fig. 1). Each vector is the distance-weighted mean of the three hour means at the three closest stations. A slight shoreline distortion results from the gridpoint resolution

the night the breeze at SS is systematically stronger than that at RI by 20 to $30 \%$. The breeze at PU near SS is even stronger. This produces a curl of the wind field over the central and eastern part of the deep lake basin. This curl is evident when the wind field over the lake is plotted (Fig. 7) for a typical early morning situation. Each wind vector has been established as the mean of the nearest three stations. While this presentation neglects the three dimensionality of the lake-land breeze it is still representative for the overall wind vector distribution. A strong cross-basin funneling is seen in the central part of the basin with a noticeable decrease towards the eastern end of the lake. Over the western part of the lake basin wind are generally weak and no organization of the wind field over longer distances is obvious.

\section{Long fetch wind events}

Winds which enter the lake basin from the southwest have a rather long fetch and thus may be important in the generation of transport and mixing. Therefore their structure during summer months was also investigated. During the summer of 1987 a continuous record for the steamer station at SS was obtained. In order to evaluate how often winds entering the lake basin at the Petite Lac end reach the SS shoreline in the central part of the Grand Lac, a correlation analysis between the wind vectors at $\mathrm{CO}$ and SS was carried out. We selected data in the long fetch sector $210^{\circ}$ to $260^{\circ}$ for the whole period and retained only those velocity vectors above $2 \mathrm{~m} \mathrm{~s}^{-1}$ since low velocities are not of interest for the present study. A linear regression analysis of these data resulted in a correlation coefficient of $c=0.81$ and an exponent of $a=1.02$ with a standard error of \pm 0.04 was found. This indicates that during periods of elevated wind speeds the two wind fields about $30 \mathrm{~km}$ apart are well correlated. Therefore the long-term record of $\mathrm{CO}$ may be used to determine some aspects of the event structure for winds from this sector.

For each month of the summer, using a seven year time series (1981-1987), the duration of the wind events above a given wind speed and the frequency of these events were found. The average over the seven year period was then calculated. The results for 2 speed classes of winds above $2 \mathrm{~m} \mathrm{~s}^{-1}$ and above $5 \mathrm{~m} \mathrm{~s}^{-1}$ are given in Fig. 8. Between May and October the duration of individual events for speeds above $5 \mathrm{~m} \mathrm{~s}^{-1}$ was between 1 and 2 hours and changed little; for the greater than $2 \mathrm{~m} \mathrm{~s}^{-1}$ class there is a drop in early summer and a strong increase in the fall. The frequency of events also varies. During early summer (May) almost $30 \%$ of the events with speeds above $2 \mathrm{~m} \mathrm{~s}^{-1}$ exceed speeds of $5 \mathrm{~m} \mathrm{~s}^{-1}$. During summer peak (June to August) the duration of $2 \mathrm{~m} \mathrm{~s}^{-1}$ events drops slightly and the frequency is reduced by $30 \%$. Again, in 30 to $40 \%$ of these events, winds can be expected to exceed $5 \mathrm{~m} \mathrm{~s}^{-1}$. During late summer (September, October) the duration of $2 \mathrm{~m} \mathrm{~s}^{-1}$ events increases by $50 \%$ while the frequency does not greatly change with respect to the summer situation. Thus, during summer wind events are shorter and of higher velocity. These characteristics are typical for thunderstorm activity

\section{Response of the lake to wind forcing}

We have shown that the wind field over Lake Geneva during its most strongly stratified period from May to October is characterized by a strong spectral peak at the 

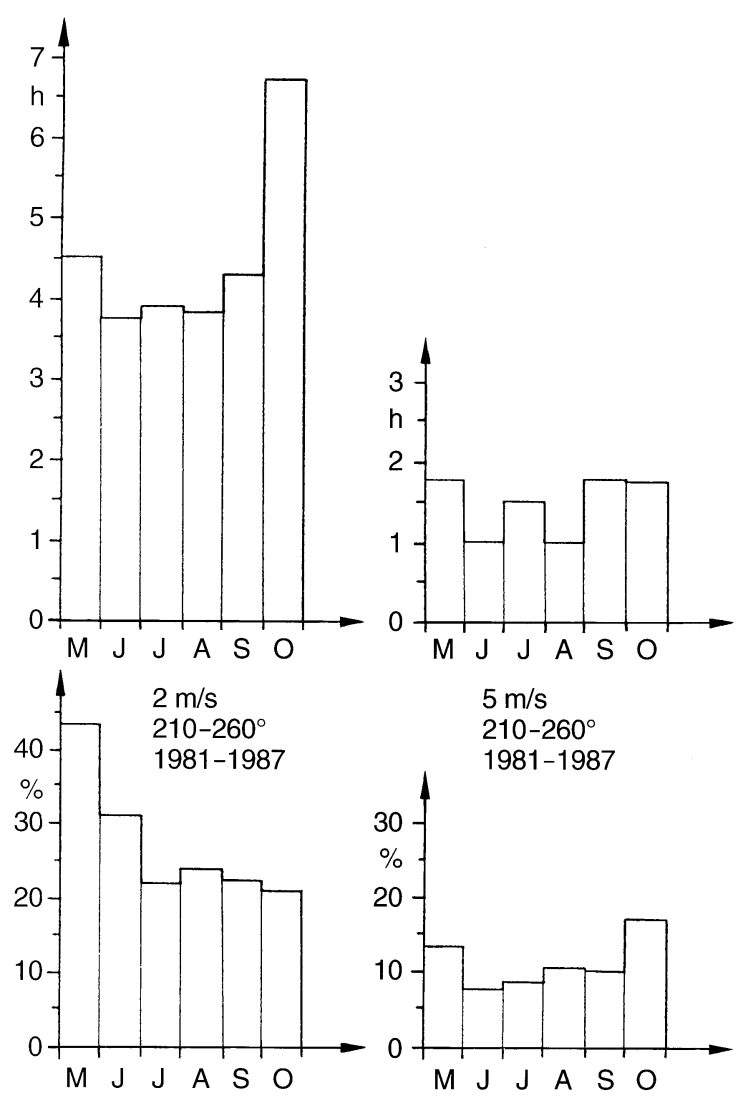

Fig. 8. The event structure of winds from the sector $210^{\circ}$ to $260^{\circ}$ (SW; 'vent') recorded at $C O$ over the 6 year period 1981-1987 and segmented into monthly subsets. Two classes of wind speed were analyzed: (a) winds above $2 \mathrm{~m} \mathrm{~s}^{-1}$ and (b) winds above $5 \mathrm{~m} \mathrm{~s}^{-1}$. For each class the diagrams shown are: top: mean monthly duration of event; bottom: mean monthly occurrence of events

diurnal lake-land breezes and to some extent the NE and the SW winds. We now turn to a comparison with the current and temperature data measured in the lake to examine the response.

\section{Downwelling caused by long fetch winds; Kelvin waves}

The direct effect of the long fetch winds NE and SW on the lake dynamics can be documented by upwelling and downwelling of the thermocline. The effect of NE winds on the density structure has been observed at several occasions. An example is given in Fig. 9 for 4 July 1989. A NE wind of about $6 \mathrm{~m} \mathrm{~s}^{-1}$ (peak at $10 \mathrm{~m} \mathrm{~s}^{-1}$ ) had been blowing for about 24 hours from 3 July until the early hours of 4 July. Temperature profiles with a vertical resolution of $0.4 \mathrm{~m}$ and accuracy of $0.001{ }^{\circ} \mathrm{C}$ were taken at 8 stations beginning at $\mathrm{S} 1$ in the Grand Lac and ending at S8 in the Petit Lac (see Fig. 1 for station locations) almost along the lake axis. As all profiles were taken within a $2 \mathrm{~h}$ time span which is much less than the inertial period of about $17 \mathrm{~h}$, the results can be considered as quasisynoptic.

The NE affects the lake west of PU. Between station S2 where no NE effect is expected and station S8 near the

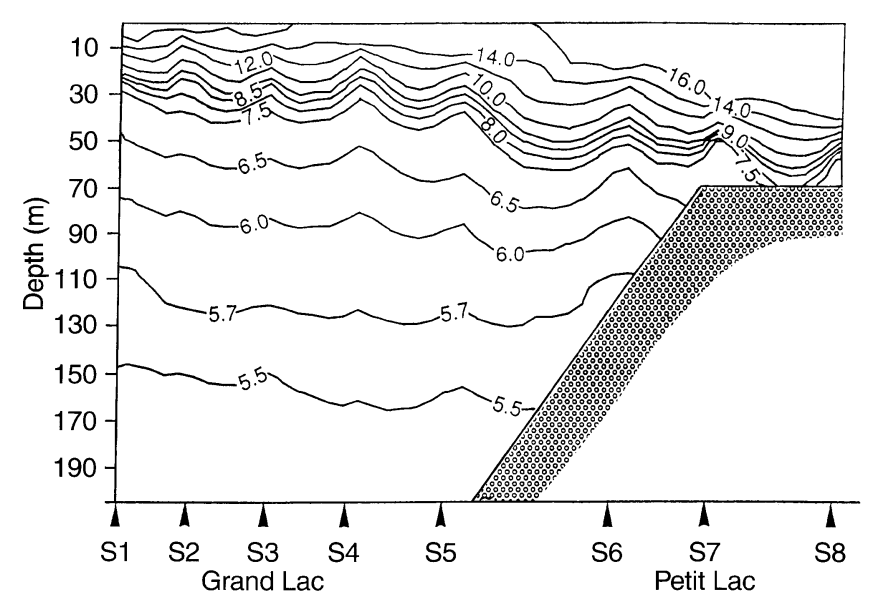

Fig. 9. Isotherm pattern resulting from a NE wind on 4 July 1989. The diagram is constructed from temperature profiles taken at stations indicated on the bottom. For station location see Fig. 1

downwind end of the NE fetch, the thermocline is depressed from about $20 \mathrm{~m}$ to about $40 \mathrm{~m}$ (Fig. 9). At the same time the temperature gradient in the epilimnion is progressively eroded along the path of the NE and at station S8 the epilimnion is isothermal. Along the NE path, the temperature gradient in the thermocline becomes progressively sharper. Several similar temperature patterns have been recorded over the years. They are only observed when the NE blows longer than $24 \mathrm{~h}$.

Basin-wide internal Kelvin waves have not been recorded during our measurements. As has been documented above, significant downwelling which can lead to the generation of Kelvin waves occurs rarely and requires time scales of wind events much longer than the typical long fetch event duration we have found in the wind analysis. Therefore Kelvin waves will not be expected to occur frequently.

\section{Currents driven by diurnal wind}

Evidence for the direct effect of diurnal winds on transport in the lake is provided from current measurements taken near RI in the summer of 1989. A field station was located about $60 \mathrm{~m}$ off-shore with a current meter placed at $3.5 \mathrm{~m}$ depth and operated for three weeks during August. No strong winds occurred during this time and surface wave effects on the measurements were negligible. Significant correlation $(0.72)$ between the currents and the wind measured at PU (no wind measurements were taken at RI during that year) exists only around the diurnal period. Current speeds which correspond to this diurnal pattern are rather weak, about 3 to $4 \mathrm{~cm} \mathrm{~s}^{-1}$. Instruments placed concurrently nearby at depths below $6 \mathrm{~m}$ however show no diurnal pattern. Other current measurements carried out over the years at depth 5 to $10 \mathrm{~m}$ did not show diurnal patterns. Thus directly driven diurnal currents exist but appear to be restricted to the very near surface layer. 


\section{Large-scale direct circulation}

Since we have observed a curl in the diurnal wind field, a test of the direct circulation pattern proposed by Strub and Powell (1986) will be made. For this we examined summer time current recordings which have been made over the past 15 years in this lake. Strub and Powell (1986) have suggested three important aspects:

Long-term mean circulation pattern. Mean current vectors from different stations taken along the north shore in different years show consistently westward transport (stations P, V, L, VI; Fig. 10). In the transect 1988, mean current vectors at $12 \mathrm{~m}$ depth (SP1 to SP8; Fig. 10) clearly show the transverse leg of a cyclonic circulation established in this cross section. Recent measurements on the south shore again match the pattern of a cyclonic circulation (PP; Fig. 10). These measurements, taken over a number of years at different locations of the central basin show a consistent cyclonic circulation in gyre turning in the eastern central part of the deep basin.

Mean current velocities. Residual circulation currents have low mean and high variance with cyclic current direction reversals whereas direct circulation is characterized by steady means and constant directions. As is evident from Fig. 11, currents in Lake Geneva below the depth of influence of SW events are rather steady and constant in direction. Strub and Powell (1986) cited

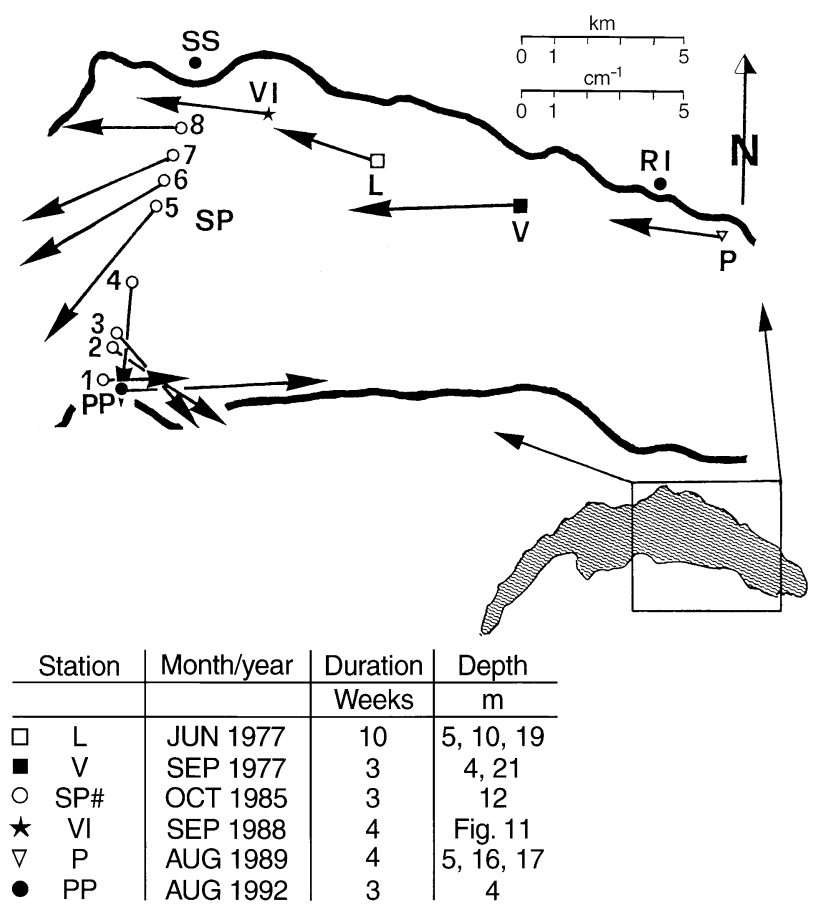

Fig. 10. Mean current vectors recorded at around $10 \mathrm{~m}$ depth in the central basin of Lake Geneva. The year and the duration of each campaign and depths of measurement are indicated. Data at stations SP1 to SP8 were recorded simultaneously. For depths at station VI refer to Fig. 11. The area of measurements on the lake has been indicated in the inset at right bottom around $5 \mathrm{cms}^{-1}$ as typical mean values for the Lake Tahoe simulation. For station $\mathrm{L}$ we have calculated mean speeds over consecutive three day periods. Taking the mean of these means we find a mean speed of $4.2 \mathrm{~cm} \mathrm{~s}^{-1}$ and a variance of $4.06 \mathrm{~cm}^{2} \mathrm{~s}^{-2}$. For about half of the three day subsets the variance is even smaller than this mean value. Similar results can be obtained from other stations. Again, this agrees with the concept of direct circulation.

Depth penetration. Strub and Powell (1986) had argued that direct circulation should penetrate downwards into the thermocline layers. In order to investigate this point, current measurements from September 1988 have been plotted in Fig. 11 as progressive vector diagrams. During this period the top of the thermocline was at about $15 \mathrm{~m}$ placing the lowest two instruments into the thermocline layer. Overall there is again cyclonic transport at all instrument depths well down into the thermocline. Only the currents above the thermocline show occasional reversals of limited duration and more pronounced closer to the surface (responses to SW wind events). Cyclonic circulation is always reestablished in between within the water column down to the metalimnion. We also find consistent cyclonic transport in the thermocline at station L at $19 \mathrm{~m}$ depth, $\mathrm{V}$ at $21 \mathrm{~m}$ depth, $\mathrm{P}$ at $17 \mathrm{~m}$ depth and VI at $20 \mathrm{~m}$ depth (station location see Fig. 10). Thus there is another field evidence for this aspect of the direct circulation concept.

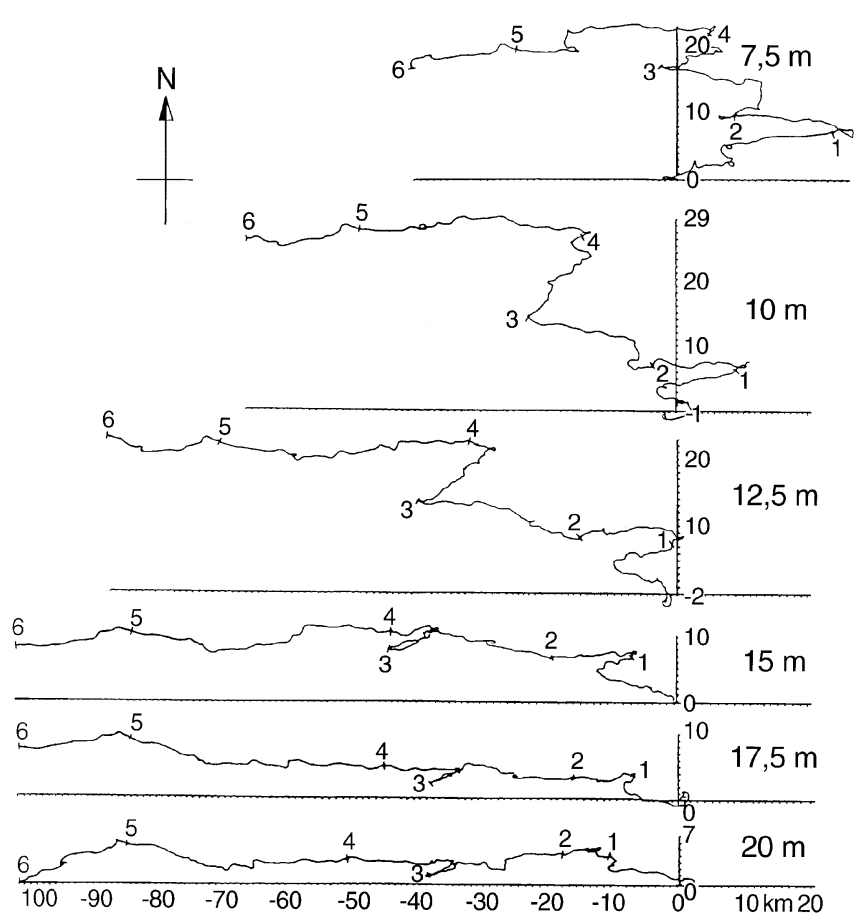

Fig. 11. For station VI (see Fig. 10 for station location). Progressive vector diagrams of six depths recorded simultaneously during the mooring period in September 1988. Data sampling interval was 5 min. Negative directions are westward. Tick marks on the curves were drawn every five days and are labeled in consecutive order 


\section{Discussion}

An analysis of wind records from shore stations around Lake Geneva shows that a periodic diurnal wind dominates the wind field during summer. The strong correlation between wind and air temperature at the diurnal frequency suggests that this diurnal wind is a lake-land breeze with typical wind speeds of $2-3 \mathrm{~m} \mathrm{~s}^{-1}$. There was evidence that the local topography modifies the lake-land breeze pattern in some parts of the basin and leads in general to spatially variable distributions of wind stress around the lake. From the distribution of the wind vectors, it appears that the convergence/divergence pattern of the diurnal wind is not symmetrical to the lake's axis.

A curl in the diurnal wind field along the northern shore is established in our analysis and can again be attributed to the effects of topography. Our observation of a westward strengthening of the breeze during night hour is supported by observations made by LeFranc (1923). He reported that between sunset and sunrise a permanent and strong breeze is established each night over Morges which is located $4 \mathrm{~km}$ to the west of SS. This wind, known as "Morget" reaches typical wind speeds of $8 \mathrm{~m} \mathrm{~s}^{-1}$ often even passing this and causing whitecapping (LeFranc, 1923; p. 17). He did not observe any significant wind in the eastern part of the lake. This "Morget", combined with our observation will cause an even stronger nightly eastwest curl along the northern shore and may well explain why the winds at the opposing south shore stations are veering to an along-shore direction. Considering that this "Morget" wind blows across the section of the lake where we found in our current measurements the establishment of the cross-lake currents, this wind may well be taken as an important component in the development of the gyral current pattern.

Lake responses to wind forcing predicted by classical concepts require a homogeneous distribution of the wind field. We have shown that storm events come closest to a homogeneous distribution. However, during the summer period they have generally short duration which is not sufficient to generate strong lake responses. Therefore, typical responses such as downwelling, direct wind driven currents and internal waves have been observed in Lake Geneva, but their contribution is limited in time and space and most often rather weak.

It has been shown that much longer event durations are needed to create situations that may subsequently generate the predicted response. From the mean conditions of a NE event, a fetch of $30 \mathrm{~km}$ and a wind speed of $5 \mathrm{~m} \mathrm{~s}^{-1}$ for the prevailing stratification conditions, we observe thermocline tilting and epilimnion mixing. In this case, a $24 \mathrm{~h}$ duration of a wind event is needed to create conditions approaching those of the steady state. Upwelling at the upwind side predicted by Imberger and Hamblin (1982) is absent. Thermocline displacements of this magnitude generate strong currents. Current measurements taken during NE events near the lake bottom east of station S7 (Fig. 1; Lemmin et al., 1988) show events of currents of more than $25 \mathrm{~cm} \mathrm{~s}^{-1}$. These currents can resuspend sediments thus influencing the trophic state of the lake over much longer periods of time.
The event statistics show that these events are very rare on this lake. In consequence, we did not observe basinwide Kelvin waves or residual circulation. This agrees with Mortimer (1983) who when investigating internal oscillatory responses of Lake Geneva to wind impulses, found the lake's responses were episodic, short-lived, characteristically intermittent and very sensitive to the duration and timing of the wind force. Internal seiching is not an important aspect of dynamics in Lake Geneva. This is different from smaller lakes where internal seiching was found to be the principal response of stratified lake dynamics (Lemmin, 1987).

None of the responses predicted for homogeneous winds can explain the observed current pattern of a steady cyclonic circulation. In the central part of the lake basin, aspects of this pattern have consistently been detected over several years and for time periods of several months at different points. It can therefore be considered as an important feature of water mass movement in Lake Geneva. Recently Schwab et al. (1995) have suggested that steady cyclonic in large lakes can be caused by internal baroclinic pressure gradients producing a domed thermocline. They have shown through numerical simulation that resultant currents may have nearshore velocities of several $\mathrm{cm} \mathrm{s}^{-1}$. However the strength of the current is inversely proportional to the lake bottom slope. The mean bottom slope in Lake Geneva is about 30 times steeper than that of the model basin. For the case where all other conditions are equal, in Lake Geneva, current velocities will fall below $1 \mathrm{mms}^{-1}$ and the contribution due to internal baroclinic pressure gradients becomes negligible. We have carried out some temperature transects in the shore region (Zhang, 1994) but did not observe a domed thermocline.

However, the observed current pattern can be explained by the concept of direct circulation resulting from the wind stress curl over the lake. Furthermore, we observe all of the essential features of the direct circulation predicted by Strub and Powell (1986) in a numerical simulation of Lake Tahoe. These features are: steady currents with means close to instantaneous speeds, constant current directions, movement in the epilimnion and the thermocline layers in the same direction and internal waves with small amplitudes. It appears that the Lake Geneva data provide the first field verification of this concept.

From the data available, we cannot determine the along axis dimension of this gyre towards the east nor can we say anything about the existence of a two-gyre pattern which has been shown to exist in numerical simulation studies. However, fishermen based in Buchillon and working in the western part of the lake indicate that drifting nets put out during the summer in this part of the lake have a clear tendency to move in a gyral pattern confined to the western part of the lake and being the counterpart to the one we have evidenced clearly in the eastern central part. The data and the observations together document that during summer time stratification the current field of Lake Geneva is steady and organized on mesoscales. This circulation can also explain the heavy metal tracer distribution which was observed (Rapin et al., 1978) since the 
direct circulation currents are steady and sufficiently strong. The gyral pattern has important consequences for residence time and the spatial distribution of any nutrients or pollutants such as heavy metals within the lake system.

A difference between the observed direct circulation in Lake Geneva and the simulation for Lake Tahoe is in the sense of the rotation of the gyre. Strub and Powell (1986) found the dominance of an anticyclonic gyre in their modeling of Lake Tahoe currents. We observed a cyclonic gyre in Lake Geneva. Some evidence in support of the latter is found in the literature: Stewart and Hollan (1984) investigated the epilimnion circulation in Lake Constance in a physical model study and found the dependence of the sense of rotation of the observed gyre on the direction and the sense of the curl of the wind field. Early field measurements provide evidence that in Lake Constance a cyclonic gyre is more often found (Auerbach, 1939; Elster and Einsele, 1937; Pulvermüller, personal communication 1993). Field measurements from Lake Biwa, Japan, (Endoh et al., 1981) also give evidence of the dominance of a steady cyclonic summer time gyre. No wind field data from those two lakes have been reported, but Endoh (1986) suggests that a wind field curl exists over Lake Biwa (making the observed pattern a direct circulation pattern) and stresses the importance of detailed wind field studies.

The pattern that evolves in Lake Geneva is one of slow but steady vertical mixing caused by a steady direct circulation occasionally disturbed by short events of stronger mixing due to long fetch storm events. This is reflected in the dynamics of the summer time stratification where the thermocline progresses steadily downward and a temperature gradient remains in the epilimnion at all times. Neither an upper mixed layer nor a 'step-type' temperature profile, both indications of strong wind event mixing (Imberger and Patterson, 1989), have been observed in several years of regular temperature profiling (Michalski and Lemmin, 1995).

\section{Conclusion}

We have shown that the wind field over the lake during the period of stratification is governed by the relatively weak diurnal thermal winds, the lake-land breeze. Winds of long fetch are potentially more powerful but they are rare and are of short duration ( $2-5 \mathrm{~h})$ during summer time. All dominant winds on Lake Geneva have about the same time scale of $\mathrm{O}(10 \mathrm{~h})$ and are organized on meso-scales due to topographical constraints. Thus, even though it may at times be desirable to construct the wind field over the lake from wind measurements taken on the lake, the apparent spatial and temporal variability and the threedimensionality of the diurnal wind field make it difficult to specify 'representative' measurement locations or 'representative' wind vectors.

However, from the meso-scale organization of the wind field it does not follow that the summer time current field is noisy and patchy as was concluded by Bohle-Carbonell (1991) for the winter time currents in this lake. Instead, during summer a steady cyclonic gyre with a mean speed of about $4 \mathrm{~cm} \mathrm{~s}^{-1}$ is found in the central part of the deep lake basin. The characteristics of this circulation all correspond to those found by Strub and Powell (1986) in a numerical simulation for a direct circulation set in motion by the curl of the wind field over the lake.

We conclude that the light and spatially variable diurnal wind field has important implications for the lake circulation. As Strub and Powell (1986) have pointed out the direct energy transfer from wind into circulation produces a much faster system response and can generate significant currents even under conditions of weaker winds. The observed formation of gyres produces water mass displacements different from the lake-basin end-toend transports envisioned under homogeneous wind field forcing. This fact has to be taken into consideration for transport of nutrients and pollutants.

It appears that the Lake Geneva data provide the first field verification of the concept of direct circulation. As our interpretation of scant examples from other lakes has already indicated, the response patterns that have emerged from the analysis of wind and current data of Lake Geneva should also apply to other stratified lakes of moderate size in basins of varied terrain.

Acknowledgements. C. Perrinjaquet was in charge of the field program and much of the data processing and programming. We are grateful for his care and efficiency. Many critical comments and helpful suggestions by S. A. Thorpe on an earlier version of the manuscript greatly helped to improve the presentation. We thank two anonymous reviewers who provided thorough and detailed comments.

Topical Editor D. Webb thanks D. J. Schwab and P. de Silva for their help in evaluating this paper.

\section{References}

Auerbach, M., Die Oberflächen- und Tiefenströme im Bodensee, Dtsch. Wass. Wirt., 34, 193-202; 358-366, 1939.

Bohle-Carbonell, M., Wind and currents: response patterns of Lake Geneva, Ann. Geophysicae, 9, 82-90, 1991

Cheng, R. T., and V. Casulli, On Lagrangian residual currents with application in south San Francisco Bay, California, Water Resour. Res., 13, 136-148, 1982.

Defant, F., Local winds, In Compendium of meteorology, American Meteorological Soc., pp. 655-672, 1951.

Elster, H. J., and W. Einsele, Beiträge zur Hydrographie des Bodensees (Obersee), Int. Rev. Gesamten Hydrobiol. Hydrogr., 35, 522-585, 1937.

Endoh, S., Diagnostic study of the vertical circulation and the maintenance mechanisms of the cyclonic gyre in Lake Biwa, J. Geophys. Res., 91, 869-876, 1986.

Endoh, S., I. Okamoto, and M. Nakai, Circular currents in the north basin of Lake Biwa, Jpn. J. Limnol., 42, 144-153, 1981.

Fischer, H. B., E. J. List, R. C. Y. Koh, J. Imberger, and N. H. Brooks, Mixing in inland and coastal waters, Academic, New York 483 pp., 1979.

Forel, F. A., Le Léman: Monographie Limnologique, vol. 2, F. Rouge, Lausanne, 651 pp., 1895.

Ganter, Y., Contribution à l'étude des brises du lac Léman. Swiss Meteorological Institute, Zürich, Rep. 83, 44 pp., 1978.

Graf, W. H., and J. P. Prost, Aerodynamic drag and its relation to the sea state: with data from Lake Geneva, Arch. Meteorol. Geophys. Biokl. Ser. A, 29, 67-87, 1979.

Huang, J. C. K., and P. W. Sloss, Simulation and verification of Lake Ontario's mean state, J. Phys. Oceanogr., 11, 1548-1566, 1981. 
Imberger, J., and P. F. Hamblin, Dynamics of lakes, reservoirs and cooling ponds, Ann. Rev. Fluid. Mech., 14, 153-187, 1982.

Imberger, J., and J. Patterson, Physical limnology, in Advances in Applied Mechanics, pp. 303-475, 1989.

LeFranc, G., Les vents du Léman, in En naviguant dans le passé et dans le présent 1, Libr. P. Pellisier, Thonon-les-Bains, pp. 3-46, 1923.

Lemmin, U., The structure and dynamics of internal waves in Baldeggersee, Limnol. Oceanogr., 32, 43-61, 1987.

Lemmin, U., C. Perrinjaquet, and W. H. Graf, Etude de la variation saisonière des phénomènes de mélange dans l'hypolimnion du Léman, pp. 85-95. Rappor t de la Commission internationale pour la protect ion des eaux du Léman contre la pollution (CIPEL), campagne 1987, 1988.

Michalski, J., and U. Lemmin, Dynamics of vertical mixing in a deep lake: Lake Geneva, Limnol. Oceanogr., 40, 809-816, 1995.

Monismith, S. G., The dynamic response of stratified reservoirs to shear stress, Ph.D. Thesis. University of California, Berkeley, 1983.

Mortimer, C. H., The resonant response of stratified lakes to wind, Schw. Z. Hydrol., 15, 95-150, 1953.

Mortimer, C. H., Lake hydrodynamics, Mitt. Int. Ver. Theor. Angew. Limnol., 20, 124-197, 1974.

Mortimer, C. H., Strategies for coupling of data collection and analysis with dynamic modeling of lake motion, in: Hydrodynamics of lakes, Eds. Graf W. H., Mortimer, C. H. Elsevier, Amsterdam, 1979.

Mortimer, C. H., Internal oscillatory responses of Lake Geneva to wind impulses during 1977/1988 compared with waves in rotating channel models, Communication du Laboratoire d'hydraulique 50. EPFL, CH-1015, Lausanne, Switzerland, 1983.
Pickett, R.L., and F.P. Richards, Lake Ontario mean temperature and currents in July, J. Phys. Oceanogr., 5, 755-781, 1975.

Rapin, F., E. Davaud, and J. P. Vernet, Etude générale de la pollution des sédiments du Léman, Rapp. Comm. Int. Prot. Eaux Léman Contre Pollut. (CIPEL), 294-309, 1978.

Richards, T. L., H. Dragert, and D. R. McIntyre, Influence of atmospheric stability and over-water fetch on winds over the lower Great Lakes, Mon. Weather Rev., 94, 448-453, 1966.

Schwab, D. J., and J. A. Morton, Estimation of overlake wind speed from overland wind speed: a comparison of three methods, J. Great Lakes Res., 10, 68-72, 1984.

Schwab, D. J., W. P. O'Connor, and G. L. Mellor, On the net cyclonic circulation in large stratified lakes, J. Phys. Oceanogr., 25, 1516-1520, 1995.

Simons, J. T., Verification of numerical models of Lake Ontario, part 2, stratified circulation and temperature changes, J. Phys. Oceanogr., 5, 98-110, 1975.

Simons, J. T., Circulation models of lakes and inland seas, Can. Bull. Fish. Aquatic Sci., 203, 146 pp., 1980.

Stewart, K. M., and E. Hollan, Physical model study of Lake Constance, Schweiz. Z. Hydrol., 46, 5-40, 1984.

Strub, P. T., and T. M. Powell, Wind-driven surface transport in stratified closed basins: direct versus residual circulation, J. Geophys. Res., 91, 8497-8508, 1986.

Wanner, H., and M. Furger, The Bise - climatology of a regional wind north of the Alps, Meteorol. Atmos. Phys., 43, 105-115, 1990.

Zhang, S., Dynamics of vertical mixing in Lake Geneva: overturning scales and energetics, Ph.D. Thesis No. 1254. EPFL, CH-1015, Lausanne, Switzerland, 1994. 